\title{
A new model for educational programming in global health emerges during COVID-19
}

\section{Chao Long ${ }^{1,2}$, Natalie Meyers ${ }^{2}$, Tingadini Nyoni ${ }^{3}$, Dharshan Sivaraj ${ }^{4}$, Godfrey I Muguti ${ }^{3,5}$, James Chang ${ }^{2,6}$}

\author{
${ }^{1}$ Department of Plastic and Reconstructive Surgery, Johns Hopkins Hospital, Baltimore, Maryland, USA \\ ${ }^{2}$ ReSurge International, Mountain View, California, USA \\ ${ }^{3}$ The College of Surgeons of East, Central, and Southern Africa (COSECSA), Arusha, Tanzania \\ ${ }^{4}$ Stanford University School of Medicine, Stanford, California, USA \\ ${ }^{5}$ Department of Surgery, University of Zimbabwe, Harare, Zimbabwe \\ ${ }^{6}$ Division of Plastic and Reconstructive Surgery, Department of Surgery, Stanford University Medical Center, Stanford, California, USA
}

\begin{abstract}
$\longrightarrow$
OVID-19 has disrupted in-person medical training worldwide. Although there has been a discussion of innovative educational solutions for high-income country (HIC) trainees [1-5], it is lacking for trainees in low- and middle-income countries (LMICs). This is problematic because there is already a shortage of trained medical professionals in LMICs [6]. Additionally, this shortage is felt most acutely in surgery and anesthesia. While one third of the world's population lives in Africa and southeast Asia, only 12\% of the world's specialist surgeons practice there [7]. In this article, we discuss the impact of COVID-19 on medical and surgical educational programming for trainees in LMICs, and use a case study to provide recommendations.

Many international non-governmental organizations (NGOs) and academic institutions in HICs have invested in building the global health care workforce through bidirectional partnerships and educational programming such as training workshops [8]. These in-person training visits, designed to supplement local training programs, came to a halt during COVID-19. Recognizing the importance of continuing to provide this education, virtual curricula have been developed and deployed via video conferencing applications.

This virtual format confers numerous advantages. Most notably, without the need to travel to LMICs, there are substantial cost and time savings for educators. Trainees can gain access to the most sought-after educators who previously could not participate due to time and financial restraints. This levels the playing field between LMIC and HIC trainees in terms of access to diverse content and curricula. A virtual platform can be accessed by more trainees and with greater ease, as trainees are also not required to travel to the instruction site. With higher attendance, the virtual format expands the programming's reach, as it crosses hospitals, cities, countries, and continents. Ability and ease of recording this programming further increase its reach and utilization. These recordings form a repository of educational material, which trainees can access repeatedly as needed and which can be provided to future cohorts of trainees. Altogether, these advantages make sustainability - the ever-elusive goal for all forms of global health programming - more attainable.
\end{abstract}

COVID-19 has disrupted medical training and education worldwide, which is especially concerning for low- and middle-income countries where there is an existing shortage of trained medical professionals. 


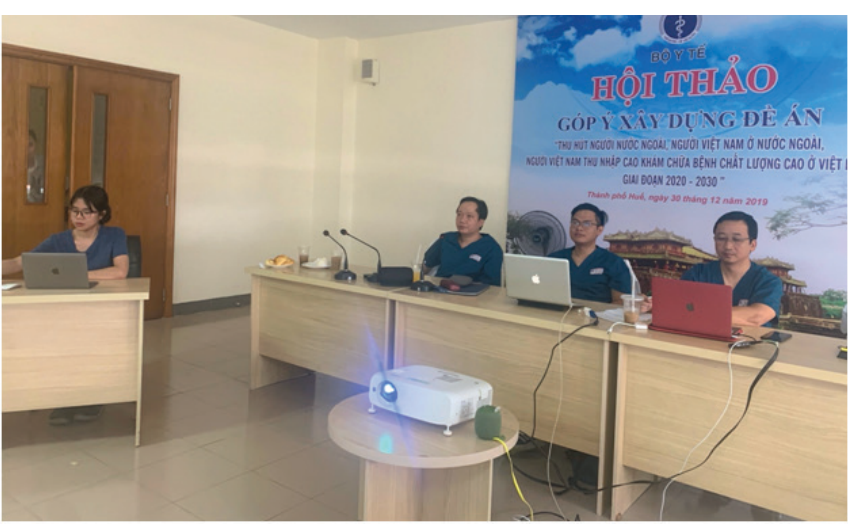

Photo: Colleagues in Vietnam participate in a virtual training session. (Source: ReSurge International, used with permission).
Virtual education however brings a unique set of challenges. First, trainees in LMICs may not have access to a reliable internet connection. In certain countries, there are frequent power outages that interfere with connectivity. Second, internet data, oftentimes paid out-of-pocket by trainees, may be prohibitively expensive given the high bandwidth and data usage that video streaming requires. Finally, because educators and trainees are typically in different time zones, the timing of the programming may preclude certain trainees from attending in real-time. Because of these challenges, we recommend that virtual educational programs consider providing financial or technical support to create a virtual learning environment locally. We also recommend all training to be recorded, so that these lessons can be watched asynchronously at any later time.

ReSurge International, an NGO dedicated to increasing access to reconstructive surgery, serves as an illustrative case example for this shift in educational programming. ReSurge provides surgical education and training via its Global Training Program $[9,10]$. Before COVID-19, this program comprised of Visiting Educators, a group of reconstructive surgeons who traveled to LMICs to deliver hands-on training. Once international travel was no longer possible, ReSurge quickly pivoted to a virtual curriculum involving several different lecture series, including a "Virtual Grand Rounds." This curriculum was developed jointly with their LMIC partners. At the time of this article's submission, it has reached more than 1200 participants from 24 countries spanning four continents. ReSurge implemented strategies to ensure useful, high quality content and close engagement from its trainees. For example, it conducts continuous needs assessments by surveying trainees and program directors. It also provides certificates of completion in order to incentivize attendance and participation. To measure its impact and track trainees'

The shift from in-person to virtual educational programming confers numerous advantages which offer a more sustainable model for education and training. We recommend the global health community to evaluate the merits of virtual training and consider its adoption, perhaps as a hybrid model, in post-COVID healthcare workforce training. progress, ReSurge administers pre- and post-lecture tests.

No global health educator would discount the value of being in-country and on-site; this allows us to perform needs assessments, build trust and goodwill with LMIC partners, understand the context of our work, and secure the buy-in that any successful global health initiative requires. Surgical education is furthermore unique from other types of medical education in that competence and mastery require not only knowledge and a command of surgical anatomy but also the technical skills for execution. For these reasons, we believe that post-COVID, educational programming in global health should reflect a hybrid curriculum including both virtual and in-person training. Before the visit, lectures can be delivered virtually, along with virtual pre-operative clinics to screen patients. This would be followed by in-person trainings that transfer diagnostic and technical skills to the trainees. Virtual training can continue after in-person trainings with additional lectures and virtual follow-up clinics. The proposed three-step hybrid program is likely to improve upon the primarily inperson models used pre-COVID because it more closely resembles existing surgical education paradigms that incorporate teaching of both technical skills and foundational knowledge. The addition of virtual training before and after in-person training allows for greater and continued emphasis on the knowledge component. This hybrid program can be repeated quarterly at host hospitals to create a continuous cycle of surgical education.

COVID-19 forced us to adapt, however it has also provided an opportunity to innovate and reimagine medical and surgical training. By leveraging modern technologies, virtual training and a hybrid curriculum offer a cheaper, less time-intensive, easily accessible, and more sustainable model for education and training in global health.

\section{Funding: None.}

Authorship contributions: All authors were responsible for the article concept and design. CL, NM, and DS conducted the literature search. All authors contributed to the manuscript writing and editing. All authors accept responsibility to submit for publication.

Competing interests: NM is an employee of ReSurge International; she reports personal fees outside the submitted work. JC is a consultant for ReSurge International; he reports personal fees outside the submitted work. The authors completed the ICMJE Unified Competing Interest form (available upon request from the corresponding author), and declare no further conflicts of interest. 
1 Disease Surveillance C. Communicable Diseases Surveillance in Singapore 2003 Special Feature: Severe Acute Respiratory Syndrome (SARS). Minist Heal Singapore. 2004; pp.3-6.

2 Coronaviridae Study Group of the International Committee on Taxonomy of Viruses. The species Severe acute respiratory syndrome-related coronavirus: classifying 2019-nCoV and naming it SARS-CoV-2. Nat Microbiol. 2020;5:536-44. Medline:32123347 doi:10.1038/s41564-020-0695-z

3 World Health Organization. WHO Coronavirus Disease (COVID-19) Dashboard 2020. Available: https://covid19.who.int/. Accessed 8 December 2002.

4 Petrosillo N, Viceconte G, Ergonul O, Ippolito G, Petersen E. COVID-19, SARS and MERS: are they closely related? Clin Microbiol Infect. 2020;26:729-34. Medline:32234451 doi:10.1016/j.cmi.2020.03.026

5 Benvenuto D, Giovanetti M, Ciccozzi A, Spoto S, Angeletti S, Ciccozzi M. The 2019-new coronavirus epidemic: Evidence for virus evolution. J Med Virol. 2020;92:455-9. Medline:31994738 doi:10.1002/jmv.25688

6 Wan Y, Shang J, Graham R, Baric RS, Li F. Receptor Recognition by the Novel Coronavirus from Wuhan: an Analysis Based on Decade-Long Structural Studies of SARS Coronavirus. J Virol. 2020;94:e00127-20. Medline:31996437 doi:10.1128/JVI.00127-20

7 Wilder-Smith A, Chiew CJ, Lee VJ. Can we contain the COVID-19 outbreak with the same measures as for SARS? Lancet Infect Dis. 2020;20:e102-7. Medline:32145768 doi:10.1016/S1473-3099(20)30129-8

8 Chen J. Pathogenicity and transmissibility of 2019-nCoV-A quick overview and comparison with other emerging viruses. Microbes Infect. 2020;22:69-71. Medline:32032682 doi:10.1016/j.micinf.2020.01.004

9 Zou L, Ruan F, Huang M, Liang L, Huang H, Hong Z, et al. SARS-CoV-2 viral load in upper respiratory specimens of infected patients. N Engl J Med. 2020;382:1177-9. Medline:32074444 doi:10.1056/NEJMc2001737

10 Kissler SM, Tedijanto C, Goldstein E, Grad YH, Lipsitch M. Projecting the transmission dynamics of SARS-CoV-2 through the postpandemic period. Science. 2020;368:860-8. Medline:32291278 doi:10.1126/science.abb5793

11 Goh KT, Cutter J, Heng BH, Ma S, Koh BKW, Kwok C, et al. Epidemiology and control of SARS in Singapore. Ann Acad Med Singap. 2006;35:301-16. Medline:16829997

12 Wei WE, Li Z, Chiew CJ, Yong SE, Toh MP, Lee VJ. Presymptomatic Transmission of SARS-CoV-2-Singapore. MMWR Morb Mortal Wkly Rep. 2020;69:411-5. Medline:32271722 doi:10.15585/mmwr.mm6914e1

13 Pung R, Chiew CJ, Young BE, Chin S, Chen MIC, Clapham HE, et al. Investigation of three clusters of COVID-19 in Singapore: implications for surveillance and response measures. Lancet. 2020;395:1039-46. Medline:32192580 doi:10.1016/ S0140-6736(20)30528-6

14 Ministry of Health Singapore. UPDATES ON COVID-19 (CORONAVIRUS DISEASE 2019) LOCAL SITUATION. MohGovSg 2020. Available: https://www.moh.gov.sg/covid-19. Accessed: 8 December 2020.

15 Lai CC, Liu YH, Wang CY, Wang YH, Hsueh SC, Yen MY, et al. Asymptomatic carrier state, acute respiratory disease, and pneumonia due to severe acute respiratory syndrome coronavirus 2 (SARS-CoV-2): Facts and myths. J Microbiol Immunol Infect. 2020;53:404-12. Medline:32173241 doi:10.1016/j.jmii.2020.02.012

16 Wölfel R, Corman VM, Guggemos W, Seilmaier M, Zange S, Müller MA, et al. Virological assessment of hospitalized patients with COVID-2019. Nature. 2020;581:465-9. Medline:32235945 doi:10.1038/s41586-020-2196-x

17 Cheng PKC, Wong DA, Tong LKL, Ip SM, Lo ACT, Lau CS, et al. Viral shedding patterns of coronavirus in patients with probable severe acute respiratory syndrome. Lancet. 2004;363:1699-700. Medline:15158632 doi:10.1016/S0140-6736(04)16255-7

18 Gandhi M, Yokoe DS, Havlir DV. Asymptomatic transmission, the achilles' heel of current strategies to control Covid-19. N Engl J Med. 2020;382:2158-60. Medline:32329972 doi:10.1056/NEJMe2009758

19 Koh X. Why are there so few coronavirus infections in Singapore's health workers? South China Morning Post. Available: https://www.scmp.com/week-asia/health-environment/article/3077345/coronavirus-why-so-few-infections-singapores-health. Accessed: 28 October 2020.

20 New BBC. Singapore hands out coronavirus tracing devices. 2020. Available: https://www.bbc.com/news/business-53216450. Accessed: 28 October 2002.

21 Tom L. Singapore Deploys Drones to Monitor Social Distancing: Will Other Tourist Destinations Follow? Skift. 2020. Available: https://skift.com/2020/08/08/singapore-deploys-drones-to-monitor-social-distancing-will-other-tourist-destinations-follow/. Accessed: 28 October 2020.

\section{Correspondence to:}

Chao Long, MD

Department of Plastic and Reconstructive Surgery Johns Hopkins Hospital 601 North Caroline Street, JHOC 8161

Baltimore, MD 21287

USA

chaolong@jhu.edu 